\title{
Momentum, June 2007
}

Population Council

Follow this and additional works at: https://knowledgecommons.popcouncil.org/ series_newsletters_momentum How does access to this work benefit you? Let us know!

\section{Recommended Citation}

"Momentum, June 2007," newsletter. New York: Population Council. 


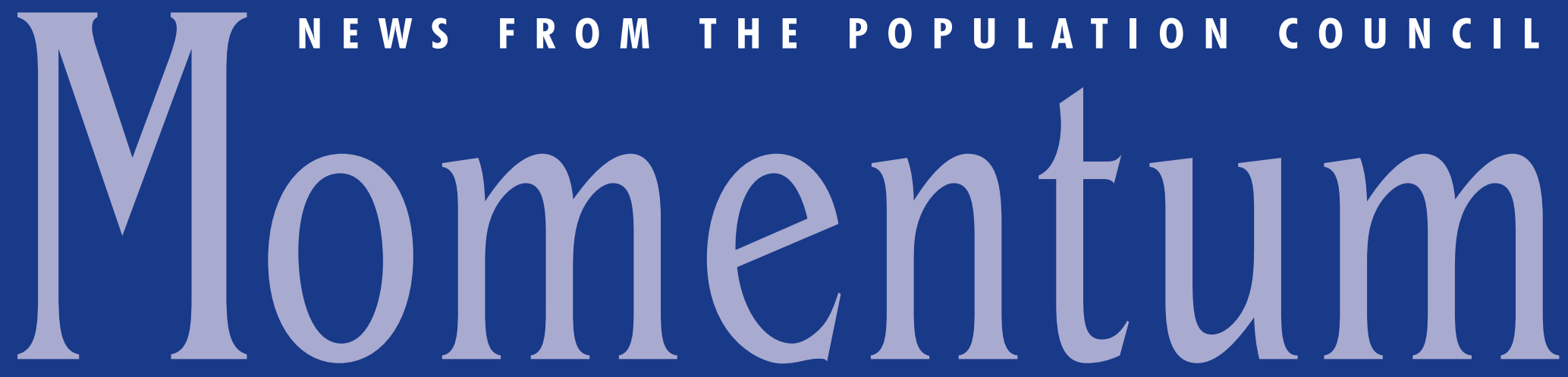

J U N E 20007

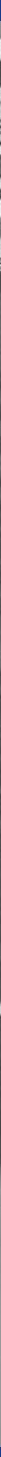

AIDS-awareness comic books in Hindi, Bengali, and English.

See "The Council Makes the Sports Pages," page 2.

\begin{tabular}{|c|c|}
\hline The Council Makes the Sports Pages & Transitions \\
\hline $\begin{array}{l}\text { Protecting Bolivian Mothers and } \\
\text { Their Babies from Syphilis }\end{array}$ & $\begin{array}{l}\text { SMART Practices in Pakistan } \\
\text { Horizons' Rutenberg to Head }\end{array}$ \\
\hline Analysis & Council Collaborator Honored by \\
\hline $\begin{array}{l}\text { Dissemination: Making Results } \\
\text { Known }\end{array}$ & $\begin{array}{l}\text { Ghana's President } \\
\text { Advancing the Use of Women's }\end{array}$ \\
\hline $\begin{array}{l}\text { Emergency Contraception in } \\
\text { Bangladesh } \\
\text { Gifts of a Lifetime }\end{array}$ & $\begin{array}{l}\text { HIV-prevention Products } \\
\text { Insights for Microbicides } \\
\text { Introduction }\end{array}$ \\
\hline
\end{tabular}




\section{Carraguard Trial Progresses to Data Analysis}

$\mathrm{O}$
$\mathrm{N} \mathrm{MARCH} \mathrm{31,} \mathrm{the} \mathrm{Population}$

Council completed data collection

in the large-scale clinical trial of the Council-developed microbicide gel, Carraguard $^{\circledR}$. The trial was conducted in collaboration with researchers at three sites in South Africa, where high prevalence of HIV in the study communities makes it possible to assess in a relatively short time whether Carraguard prevents infection. Data analysis is under way. Results-indicating the magnitude of effect of Carraguard in preventing HIV transmission when the gel is expected by the end of the year.

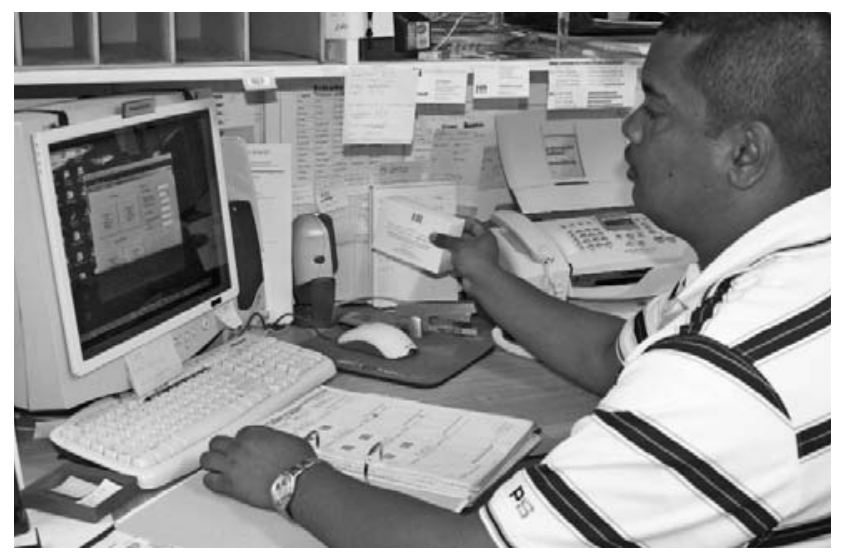

Digital scanners were used to collect and record information during the Phase 3 trial of Carraguard. used during vaginal intercourse-are
Carraguard is the first female-controlled product developed specifically as a microbicide to complete a large-scale clinical efficacy study. More than 6,000 women were enrolled and randomly assigned to use Carraguard and a condom or a placebo gel and a condom before each act of vaginal intercourse. Participants visited the clinic quarterly for as long as two years, during which time they received safer-sex counseling, pelvic exams, HIV tests, and testing and treatment for sexually transmitted infections, in addition to condoms and the study gel.

\section{DISSEMINATION:} MAKING RESULTS KNOWN

A T THE Population Council-cosponsored part of the 51st Annual UN Commission on the Status of Women held in February, talk on "Identifying and Reaching the Girls Most Vulnerable to HIV" to an audience of 250 policymakers, program implementers, and donors.

In December, Council scientist Gary Hunnicutt delivered the keynote address at the New York Microscopical Society's winter banquet, where he spoke on "Microscopic techniques to understand sperm function." In May, he was one of 70 invitees at the 2nd International Meeting on Septin Biology in Monte Verità, Switzerland.

Horizons Research Director Julie Pulerwitz co-authored "Gender, sexual behavior, and vulnerability among young people," a chapter in Promoting Young People's Sexual Health: International Perspectives, a collection of key writings celebrating the work of the UK's Department for International Development-funded research program, Safe Passages to Adulthood.

In the latter part of 2006, Horizons researchers published seven articles in six peer-reviewed journals: AIDS and Behavior, AIDS Care, AIDS Education and Prevention, Health and Human Rights, Health Policy and Planning, and Reproductive Health Matters. "Panel Discussion on Girls and HIV/AIDS," Council researcher Kelly Hallman delivered a

\section{Emergency Contraception in Bangladesh}

A N ESTIMATED 1.2 million unplanned pregnancies occur in Bangladesh each year. Although contraceptives are widely available in Bangladesh, until recently there has been no emergency method in the public sector for preventing pregnancies following unprotected sex. By February 2007, thanks to technical assistance from the Population Council in collaboration with the United Nations Population Fund, the Bangladesh Ministry of Health and Family Welfare had trained all of the approximately 45,000 providers in the National Family Planning Program in emergency contraception, and health-care facilities were stocking educational brochures and emergency contraceptive pills (ECPs). A management information system to monitor program implementation and use of ECPs is now in place. At present, an estimated 20,000 ECPs are being distributed every month in this country of 162 million.

The "Emergency Contraceptive Pills: South East Asia RegionalTraining Manual," developed as part of the followup to the successful Council-led three-year pilot project that tested the introduction of ECPs in Bangladesh, is being used in more than ten other countries. The manual and a companion slide show are available for free at www.popcouncil.org/frontiers/projects_pubs/topics/ SLR/ECP_TrainingManual.html.

“Enhancing Utilization of Research Findings: Scaling Up ECP Program to the National Level in Bangladesh" was one of the more than 180 projects fielded in 2006 by the Council's Frontiers in Reproductive Health program, which is funded by the United States Agency for International Development.
If Carraguard is shown to by the Medicines Control Council, the regulatory agency in South Africa, the Population Council will work partners and international organizations to facilitate affordable access to Carraguard in South Africa and explore introduction of the product in the developing world. Council biomedical scientists have continued to develop second-generation microbicide candidates.

\section{Gifts of a Lifetime}

$\mathrm{N} E A C H$ of the past two years, the Population Council has received generous bequests from individuals devoted to furthering the Council's mission of improving lives. Such gifts often are transformative in nature by enabling the underwriting of a major program area or work in a specific region of the world. Former Council friend and colleague Carl Frisén, a highly respected member of the population community who was the first chief of the United Nations Economic and Social Commission for Asia and the Pacific (ESCAP) and who worked for many years in Thailand, chose to designate the proceeds of his trust for Council activities in Asia.

Several Council supporters have told us of their plans to bequeath money to the Council, and we have had the opportunity to express our gratitude to them. If you are considering such a gift, please let us know. Our goal is to work with you to ensure that your philanthropic objectives are realized. We want to celebrate in your lifetime the legacy you plan to provide to better the lives of future generations.

\section{A NEW GIVING OPTION}

Legislation recently enacted by Congress to encourage broader charitable giving offers an attractive but limited opportunity to make tax-free gifts in 2007 using distributions from your individual retirement account (IRA). Donors must be at least $70 \frac{1}{2}$ years old. Gifts as great as $\$ 100,000$ can be made, but in order for them to be tax deductible, they must be transferred directly to the recipient organization by your IRA custodian. Your custodian can provide further details about this IRA rollover provision.

Ruth Kalla Ungerer, the Council's director of development, is available at (212) 339-0515 or at rungerer@popcouncil.org to answer questions about making such one-time gifts in support of the Population Council's work. 
$\mathrm{T}$ HE POPULATION COUNCIL has collaborated with researchers in Thailand since 1959, and established an office in Bangkok in 1969 to provide technical and financial assistance to the government, to universities, and to NGOs working on child health and family planning programs. The Bangkok office served as the regional office for South and East Asia from 1978 to 1995, when the regional base moved to New Delhi. Since then, it has continued to oversee Council activities in neighboring Cambodia, China, Laos, Myanmar, and Vietnam.

"In the almost 50 years the Population Council has had a presence in Thailand, Thai institutions have evolved from being recipients of our technical assistance to being valued partners in providing technical assistance to other countries in the region," says Anrudh Jain, vice president of International Programs. "This is exactly how 'building professional capacity' is meant to work."
In view of this successful transition, the Council is now implementing a new mode of operations in Thailand. The Bangkok office was closed in December 2006, and in January of this year, Council President Peter Donaldson signed a memorandum of understanding

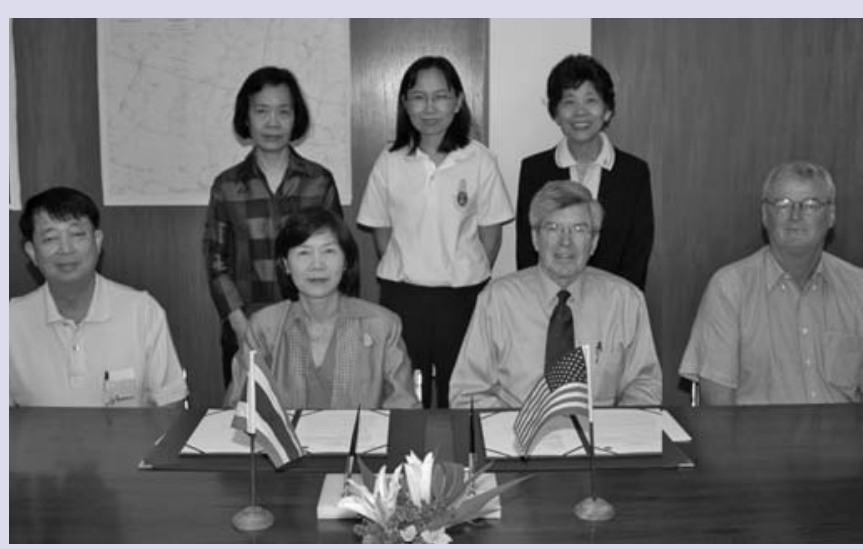

Council President Peter Donaldson with IPSR Director Churnrurtai Kanchanchitra and IPSR staff at the January 2007 signing. with the Institute for Population and Social Research (IPSR) at Mahidol University (see photo). By the terms of the memorandum, the Council and IPSR have agreed to work as partners to develop local and regional programs for technical assistance in the areas of population, development, and health.

Changes also are being made in other countries. The Council recently opened offices in Addis Ababa, Ethiopia, and Khartoum, Sudan, to support its growing body of research in Africa. Work to address the vulnerabilities of married adolescent girls and migrant adolescents in Ethiopia continues in collaboration with the Ministry of Youth and local faith-based groups; in Sudan, capacity building and relevant research under way since 2004 is being expanded.

\section{SMART Practices in Pakistan}

A CCORDING TO UNICEF, a woman in Pakistan has a one-in-31 lifetime risk of death from causes related to pregnancy and childbirth. Although the country has made important progress recently, it ranks 183 rd out of 220 countries in terms of infant mortality.

The Safe Motherhood Applied Research and Training (SMART) project was developed by Council researchers to investigate ways to reduce maternal and perinatal mortality in the Pakistani province of Punjab. (Perinatal mortality figures include both stillbirths and neonatal deaths.) The three-year project, launched in 2003, tested the effects of introducing two service-delivery methods. For the experimental interventions, 120 rural communities with a total population of about 600,000 were divided at random into a control group, a group that would receive improved health-care systems only, and another group with improved systems plus community-based interventions.

Strengthening the health-care systems primarily involved training of district health managers, medical specialists, physicians, and paramedics in the public sector. This training included technical aspects of maternal and newborn health care and the Council's "client-centered approach" (CCA) to care, which emphasizes the assessment of clients' needs and negotiated solutions to reproductive health problems.

Community-based interventions included involvement of community leaders, education of close to 34,000 women and men by means of support groups, improved transport systems, and better linkages with the health-care system. In addition, community-based providers, including government-paid community health workers and dais (traditional birth attendants), were given both technical and CCA training.

Less than two years later, the perinatal mortality rate had declined by 22 percent in the areas with an improved health-care system plus community-based interventions. No change was found in the communities that received only health-care system improvement or in the control district. The primary factors in the decline appear to have been the community education and dai training components.

The SMART project has broken the barrier between the traditional dais and modern health workers in a way that respects the dais' important position in Pakistan's traditional culture but also takes advantage of the life-saving skills of modern practitioners. As a result, the dais are increasingly bringing emergency cases to the regional hospitals. SMART also has increased awareness among mothers of danger signs during pregnancy, delivery, and the postnatal period, and improved understanding of when they should seek medical help.

In January, the Population Council hosted a seminar to present the SMART project findings to healthcare professionals, academics, policymakers, and health-care managers. Pakistan's Director-General of Health, Shahida Malik, said that training dais in accordance with the study's "lessons learned" is vital to reducing maternal and neonatal mortality and to reaching the Millennium Development Goals, a major objective for Pakistan.

At least eight Pakistani newspapers covered the release of a report of the European Commissionfunded research. The results from the study, including specific project innovations, are now being used more widely in Pakistan to strengthen maternal and neonatal health programs. For example, the Council's dai training package is currently being implemented in three large-scale interventions, and the clientcentered methodology is being incorporated into the government's new community midwife training project. Publication of the results of the project in several international medical journals is helping to ensure dissemination beyond Pakistan's borders.

\section{Momentum}

\section{(2) Population Council}

\author{
One Dag Hammarskjold Plaza \\ New York, NY 10017 \\ Phone: 212-339-0500 Fax: 212-755-6052 \\ E-mail: pubinfo@popcouncil.org \\ www.popcouncil.org
}

Momentum is a semiannual newsletter of the Population Council. Information may be reproduced without permission, provided it is distributed free of charge and the source is acknowledged. Online at www.popcouncil.org/ publications/momentum/default.htm.

The Population Council is an international, nonprofit, nongovernmental organization that seeks to improve the well-being and reproductive health of current and future generations. The Council conducts biomedical, social science, and public health research in three areas: HIV and AIDS; Poverty, Gender, and Youth; and Reproductive Health. Established in 1952, the Council is governed by an international board of trustees. Its New York headquarters supports a global network of 19 regional and country offices.

Writer Suzie Elliott

Editors Rob 0'Sullivan/Ruth Kalla Ungerer Copyeditors Robert Heidel/Karen Tweedy-Holmes Designers Y. Christina Tse, Mike Vosika

REGIONAL OFFICES

South and East Asia: New Delhi, India

Sub-Saharan Africa: Accra, Ghana

West Asia and North Africa: Cairo, Egypt

ISSN 1535-0525

(C) 2007 The Population Council, Inc. Printed in the USA on recycled paper

Photo credits-page 2 (left): Population Council/India; page 2 (right): Freddie Tinajeros; page 3 and page 6: Bev Symmonds; page 5: Karen Tweedy-Holmes 


\section{Horizons' Rutenberg to Head Expanded HIV and AIDS Program}

$\mathrm{P}$

OPULATION COUNCIL and Horizons veteran Naomi Rutenberg has been named director of the Council's recently reconfigured HIV and AIDS program.

At the time of her promotion, Rutenberg was the head of the Council-directed Horizons Program, which uses operations research to improve response to the HIV pandemic in developing countries. Rutenberg is well known within the HIV and AIDS community, having spent more than two decades conducting behavioral and program research on the virus and its effects, as well as on reproductive health. She is widely published, speaks often at conferences and seminars, and has been a principal or coinvestigator on many important research studies. cross-cutting research on identifying biological mechanisms of action, product development, clinical trials, product introduction, addressing power and gender issues, strengthening health systems, and employing sophisticated approaches to program evaluation, giving the Council the opportunity to establish leadership in important areas within the field."

Rutenberg began her tenure by asking herself and her staff fundamental questions: Based on what the Council has already accomplished, where do we want to put our emphases? What do individual scientists, researchers, program managers, or communicators need to be successful? What are the most promising ways to have a measurable impact? The answers will help to shape the program.

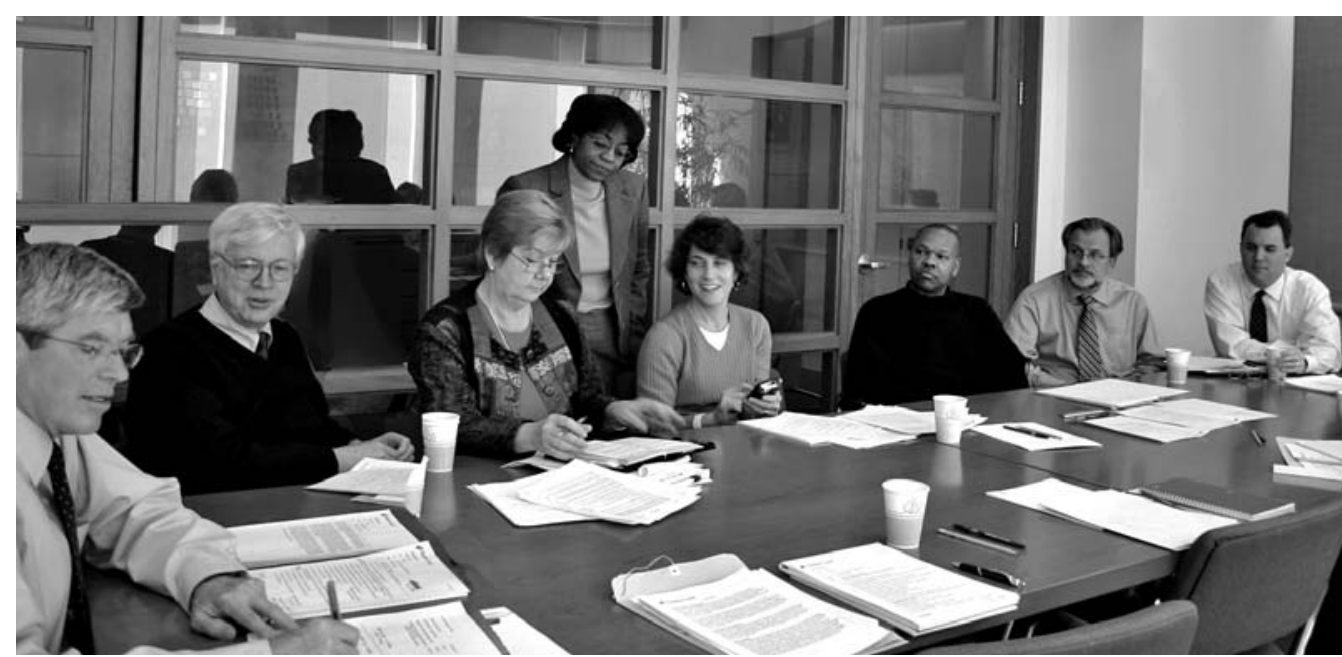

From left to right: President Peter J. Donaldson; Vice President and Distinguished Scholar John Bongaarts; Poverty, Gender, and Youth Program Director Wendy Baldwin; General Counsel and Secretary Patricia C. Vaughan; HIV and AIDS Program Director Naomi Rutenberg; Chief Financial Officer and Treasurer Kenneth L. Payne; Reproductive Health Program Director John W. Townsend; and Corporate Affairs Division Director James E. Sailer

"We at the Population Council already know Naomi Rutenberg to be a strong leader, a talented and influential researcher, and an excellent collaborator," says Council President Peter Donaldson. "Her extensive international experience, knowledge of the HIV and AIDS field, and passion for our work make her an ideal leader for our HIV and AIDS program."

The goal of that program is ambitious: to conduct research that helps to reduce new HIV infections, and mitigates the impact of AIDS on those who are infected and affected. The Council's pioneering role in microbicide development, technology introduction, and operations research makes the organization uniquely qualified to shape strategies for microbicide introduction and access.

"We have the expertise and experience to rise to this challenge," says Rutenberg. "The Council has a world-class team of biomedical and social scientists. They conduct
“We are creating a new way of working that emphasizes partnerships," she says. "For internal teams, that means integrating diverse perspectives and expertise within the Council. For external partnerships, that means linking with communities and peer organizations to address collectively the HIV pandemic in developing countries. We intend for these cross-fertilizations to foster new research and pilot programs, producing evidence for effective, equitable HIV programs and measurable impacts on HIV policies and programs."

Rutenberg received her Ph.D. in sociology and demography from Princeton University in 1993. She also holds a Masters of Arts degree in Latin American studies from the University of Florida. In addition to her considerable experience in Africa, she has worked extensively in Brazil and speaks Portuguese. She serves on the editorial committee of the Council's peerreviewed journal, Studies in Family Planning.
Council

Collaborator Honored by Ghana's President

N FEBRUARY OF 2007, President John Agyekum Kufuor of Ghana bestowed the first President's Excellence Awards for Public Services. The awards are part of the African Union's efforts to celebrate and encourage reform, productivity, and innovation at government institutions throughout Africa.

The Ghana Health Service won three of the four awards, two of them for its Community-based Health Planning and Services (CHPS) initiative, to which the Population Council has provided guidance and technical expertise since its inception in 1999. CHPS evolved from a pilot project, the Navrongo experiment, which the Population Council launched with the Ghana Health Service in northern Ghana in 1994. Among its many achievements, CHPS has reduced the mortality rate among children younger than five by two-thirds and has brought about a 15 percent decline in fertility. It has done so by changing the focus of primary health care and family planning services from in-clinic care to high-quality services provided at community and "doorstep" locations. The initiative is currently being scaled up across Ghana as the health-sector component of the government's national poverty-alleviation program.

CHPS was honored with a gold plaque as an "Innovative Partnership between the Public Service and Civil Society" and a silver plaque for "Innovative Service Delivery Improvement." Representatives from Burkina Faso, Ethiopia, and Sierra Leone have participated in study tours of CHPS sites in recent months.

\section{STAY CONNECTED}

We want to be sure all Population Council alumni have the opportunity to stay in touch through Momentum. Contact Rob O'Sullivan, manager, Annual Fund and alumni relations, at rosullivan@popcouncil.org or 212-3390511 to share your news or comments about Council projects. 
Advancing the Use of Women's HIVprevention Products

T ODAY, globally, between 17 and 21 million women are living with HIV. According to UNAIDS, women account for 60 percent of new infections in subSaharan Africa, and young women are being infected at three times the rate of young men. Clearly, solutions that focus on men alone won't work, and insisting on use of the male condom often is not within women's power. The only currently available female-initiated prevention product, the female condom, is accessible to only a tiny proportion of the women at risk of HIV.

Any strategy to slow and contain the AIDS pandemic must include expanding both the availability and women's use of prevention technologies. The unequal status of girls and women in many societies is central to the development of meaningful protection strategies. Women's economic dependence on men, discriminatory cultural practices such as early marriage, and sexual violence and coercion leave many women vulnerable to HIV and AIDS. Several types of research are needed to understand how best to introduce female-initiated prevention products within the context of such practices. With a generous grant from the Danish Ministry of Foreign Affairs, the Population Council has initiated a project to develop and test innovative approaches to making available products designed to prevent HIV transmission, such as the female condom and microbicides, which are currently being tested in clinical trials for their safety and efficacy in preventing transmission of HIV when used prior to intercourse.

The research, to be conducted in sub-Saharan Africa, aims to increase access to and use of the female condom and to prepare for accelerated introduction of other female-controlled protection products, such as microbicides, as they become available (see accompanying articles on pages 3 and 6). The results can be used to begin preventing new infections immediately while simultaneously laying a foundation for an expanded choice of HIV-prevention technologies for women to use.

\section{Insights for Microbicides Introduction}

A

S DATA analysis of the Population Council-developed microbicide Carraguard ${ }^{\circledR}$ begins, Council researchers are considering how an effective microbicide should be made available to the women who most need it. A successful microbicide would be a product-likely to be delivered in the form of a gel, foam, ring, or cream - to reduce the transmission of HIV, and possibly other sexually transmitted infections, when used during intercourse. It would be a form of protection that women could initiate and control, giving them an additional defense against HIV. (Currently, the only woman-initiated preventive product is the female condom, which so far has not achieved the widespread use health experts still work toward.)

There are dozens of candidate microbicides currently under development, several of which are slated to complete their safety and efficacy trials in 2007.* If any of these products proves sufficiently protective, the next steps are the manufacture and distribution of the product.

Given the novel nature of a microbicide product, there exists no blueprint for its introduction and integration into couples' lives or into developing-country health systems. There are, however, relevant experiences from other fields from which insights and evidence can be gleaned and applied.

With that in mind, the Council convened a meeting in March of experts in product development and introduction, direct-to-consumer marketing, clinical trials, and developing-country reproductive health and HIV/AIDS programming. Titled "Insights and Evidence from Product Introduction: Lessons for Microbicides" the day-long meeting at the Council's New York headquarters was moderated by Population Council Program Associate Martha Brady, and attended by 45 leaders of two dozen government, nongovernmental, advocacy, and donor organizations.

"The speakers brought immense experience in putting products into the hands of consumers," says Brady. "Our goal for the meeting was to be of service to the microbicides field. Our goal for protection products is to increase the number of protected acts of sex and thus the number of women protected from HIV, which is also the key public health goal."

Presenters at the meeting reviewed strategies that have been used in introducing health technologies in developing countries to generate and share ideas centered on the concept of building the platform for microbicides. Some of the issues that would affect the introduction of a microbicide product include how to explain its correct use (as emergency contraception also

*The data-collection stage of the Council's Phase 3 trial of Carraguard has been completed. See page 3 . requires); how to market a female-initiated HIVprevention product used during intercourse (as the female condom is); and how to introduce a product - the microbicide - to be used in conjunction with another product-the condom (as certain "packages" of contraceptive products require).

Sharing their expertise, speakers discussed market segmentation and product positioning; how complex messages are best communicated; and how social marketing approaches are used to initiate new behaviors for disease prevention. Questions that were raised and call for more research include how women assess their own risk of contracting HIV, how their assessments compare to their actual risk, and, if necessary, how to educate them to make an accurate assessment and take appropriate action.

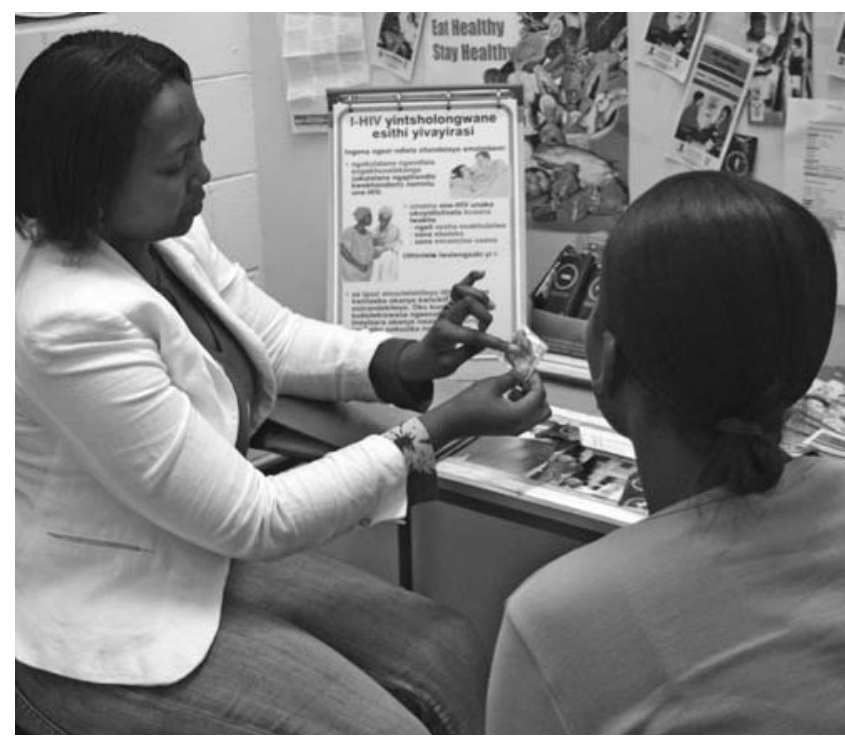

A successful product introduction must include clear instructions on how to use it.

Other areas that merit close examination concern the logistics of distribution. How will women learn to understand the product and to use it properly? And will they use it properly? The questions that were raised gave Council researchers perspective as they develop plans to introduce microbicide products to users.

"There is an urgent need for protection from HIV, and this discussion was extremely valuable," says Brady, "in recognizing questions we need to ask and identifying key features that can help guide microbicide introduction efforts."

"Lessons for Microbicides" was the second Day of Dialogue sponsored by the Council; the first, in October of 2005, explored ways of getting medicinal products into the hands of the world's poor. A 16-page report from that event is available at www.popcouncil.org/pdfs/ DayOfDialogue.pdf, and a report from the microbicides event is expected this autumn. 